\title{
Social Networking based E-Learning System on Clouds
}

\author{
Rajni Jindal \\ Associate Professor \\ Department of Computer Engineering, \\ Delhi Technological University,New Delhi
}

\author{
Alka Singhal \\ Research Scholar \\ Department of Computer Engineering, \\ Delhi Technological University,New Delhi
}

\begin{abstract}
With the recent advancements in the modern Information and Communication Technology (ICT), e-Learning has emerged as a new paradigm for learning in the modern world. There are many dimensions such as pedagogical, technological, ethical etc which are to be satisfied by the e-learning service provider to become a better option in compare to the traditional learning techniques. Among all the dimensions, technological and pedagogical dimension are among the critical dimensions, as they address issues concerning content analysis, audience analysis, goal analysis, performance analysis and infrastructural analysis. This paper proposes an E-learning Social networking site which is maintained by Cloud providers. Blending the two technologies, Social networking and Cloud computing, provides a business model for E-learning where construction of e-learning system is entrusted to cloud computing suppliers and social networking helps to improve the teaching quality and content.
\end{abstract}

\section{Keywords}

E-learning Systems, Social networking, Cloud computing, Social clouds.

\section{INTRODUCTION}

E-learning as an important mode of learning today, plays an important role in creating a good convenient learning environment. It is a good carrier of the content and provides learner a wide variety of learning materials and learning opportunities. It has lots of advantages like flexibility, diversity, measurement etc and so it is becoming a primer way for learning in the new century [1].

Key factors of E-learning are:-1) Reuse 2) Resource Sharing 3) Interoperability.

E-learning can be viewed as a way of learning in which the instructor and the student are separated by distance or time and this gap is bridged through the use of online resources. It can be any of the following technology:-

- Blogs.

- Computer aided teaching.

- Online Discussion Boards.

- Electronic education support system.

- Learning management systems.

- Virtual classrooms.

- Web-based teaching materials.
First part of the paper includes Infrastructural analysis of the E-learning system including content distribution and expansion. In traditional web-based e-learning mode, system construction and maintenance are done by the educational institutions itself. As it involves large investment and maintenance from the institution, the capital gain is not much as it should be. This is also hindering the E-learning development in the computing era. In contrast, if cloud computing is used in the e-learning model, it introduces scalability, i.e. construction and maintenance of e-learning system is done by the cloud services providers and further these services are used by the e-learning provider by paying in cost per unit. Here E-learning provider is not concerned about the infrastructural and maintenance expenses but it focus on the content quality and management [2]. Whereas, the Cloud providers have already established infrastructure, so they can utilize it for providing E-learning services without any additional investment in compare if it is done by Institution itself. In totality, it gives a Win-Win situation to both and also provides better prospects for E-learning systems.

Second part of the paper explores the universality and pedagogical dimension of the e-learning content. There is a huge amount of data available on the web, but this data is many times not accessible due to its different language and locality. The social cloud helps all the e-learning providers a common platform where they can share their data and make it universally available. The model will act as knowledge search engine where all the contents of providers will be available to the learner. This search engine will act as a social networking site between all the providers and learners. Social Clouds help learners to interact with each other and perform discussions. Learners can also give their feedbacks for the material and thus content will be well reviewed and updated. In summarized way, this paper proposes a social networking elearning site which is maintained by the cloud providers.

\section{TRADITIONAL E-LEARNING MODEL}

Traditional e-learning network is located in a campus network or an Intranet with its construction, maintenance, and investment being made by enterprise itself. There are various components of E-learning System [3]:-

Content Experts:-Content Experts are responsible for production of authorized learning material. Material can be in any form e.g. lectures notes, video courses etc. They are 


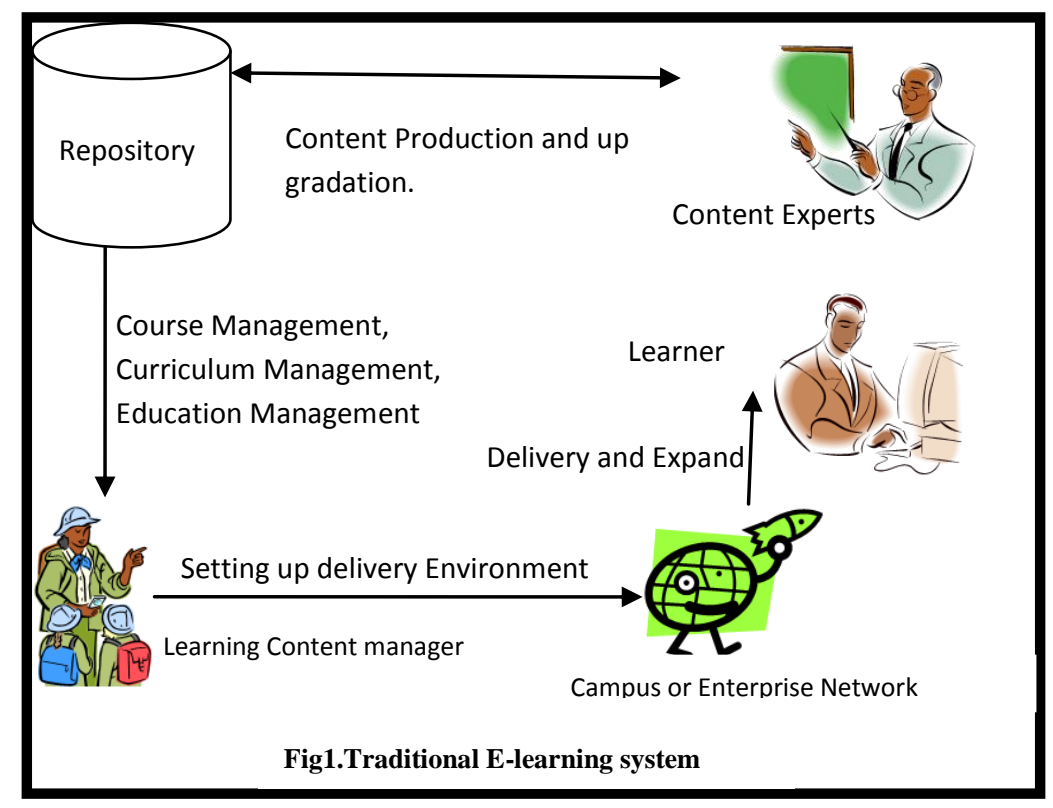

esponsible for creating good, reliable and updated learning material for the targeted learner.

Metadata \& Repository: - It contains all the learning content in form of lectures, videos etc and also the catalogs maintaining the information about the learning content like indexes, date of issue, relevant topics, keywords etc.

Learning Content Manager: A manager who is the administrator of the E-learning system, he keeps information about the registered learners, their payments, their feedbacks. $\mathrm{He}$ is responsible for structuring data, organizing reviews, tests etc.

Content Distribution:-Content distribution system is responsible for utilizing wide area network, broadband services to distribute the data. It is responsible for error-free and fast delivery of data. As it can be real-time system (virtual classrooms) time complexity is important.

Learner:-Learner is the one accessing the E-learning system. E-learning system should maintain the information about learner profile and his registration information. Learner profile information can include personal data, learning plans, learning history, accessibility requirements, certifications and degrees, assessments of knowledge and the status of participation in current learning.

\section{USING SOCIAL NETWORKING IN E- LEARNING}

A social network is a set of individuals connected through socially meaningful relationships, such as friendship or information exchange (Wasserman, Faust, Iacobucci, \& Granovetter, 1994; Wellman, 1996).

Social networks are formed when people interact with each other (Garton, Haythornthwaite, \& Wellman, 1997) and thus can be seen in many aspects of everyday life. In its most simple form, a social network is a map of all of the relevant links between the nodes being studied. As noted by Milgram (1967), the strength of a tie between two actors is much greater if they have another mutual acquaintance. In other words, the probability of two friends of an individual knowing each another is much greater than the probability of two people chosen randomly from the population knowing each another (Guare, 1990; Newman, Watts, \& Strogatz, 2002; Watts \& Strogatz, 1998). Actors with strong ties usually have some sort of common ground on which they establish their relationships (Preece, 2002; Wellman \& Gulia, 1997), and thus often constitute a subgroup. Because of the common ground, actors with strong ties - and hence representing a subgroup - often share common interests, needs, or services that provide a reason for the subgroup (Preece, 2002; Schwartz \& Wood, 1993; Wellman \& Gulia, 1997).

A Social networking can be widely explored in the field of Elearning as it is said "Knowledge which is shared is better". So the paper provides a platform where learners of common interest as well as providers who are commonly targeted by the learners are grouped together to form a network. This platform will help the various e-learning providers to communicate and share their contents and spread it to a larger audience. On the other side, learners having common interest will share and communicate their views etc. As a whole it will give a new paradigm for E-earning systems.

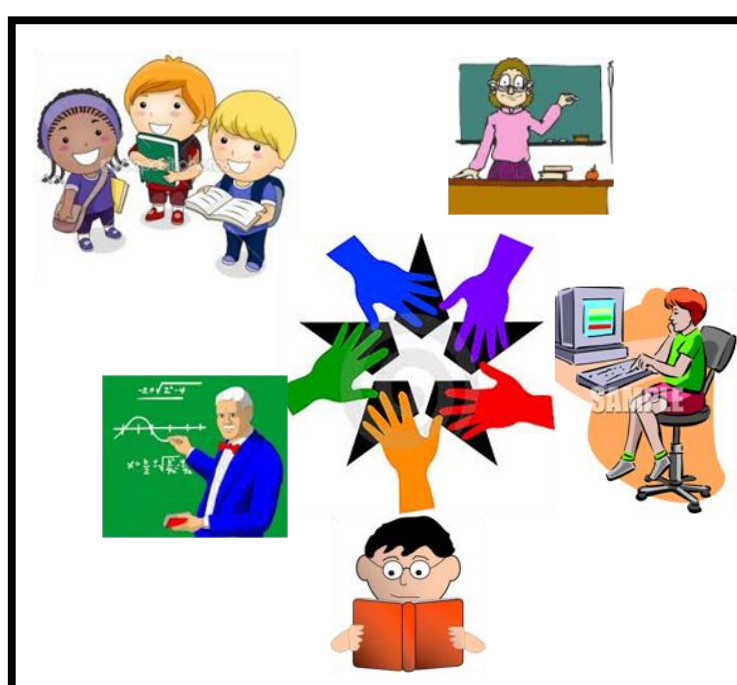

Fig2. Social Networking in E-Learning 


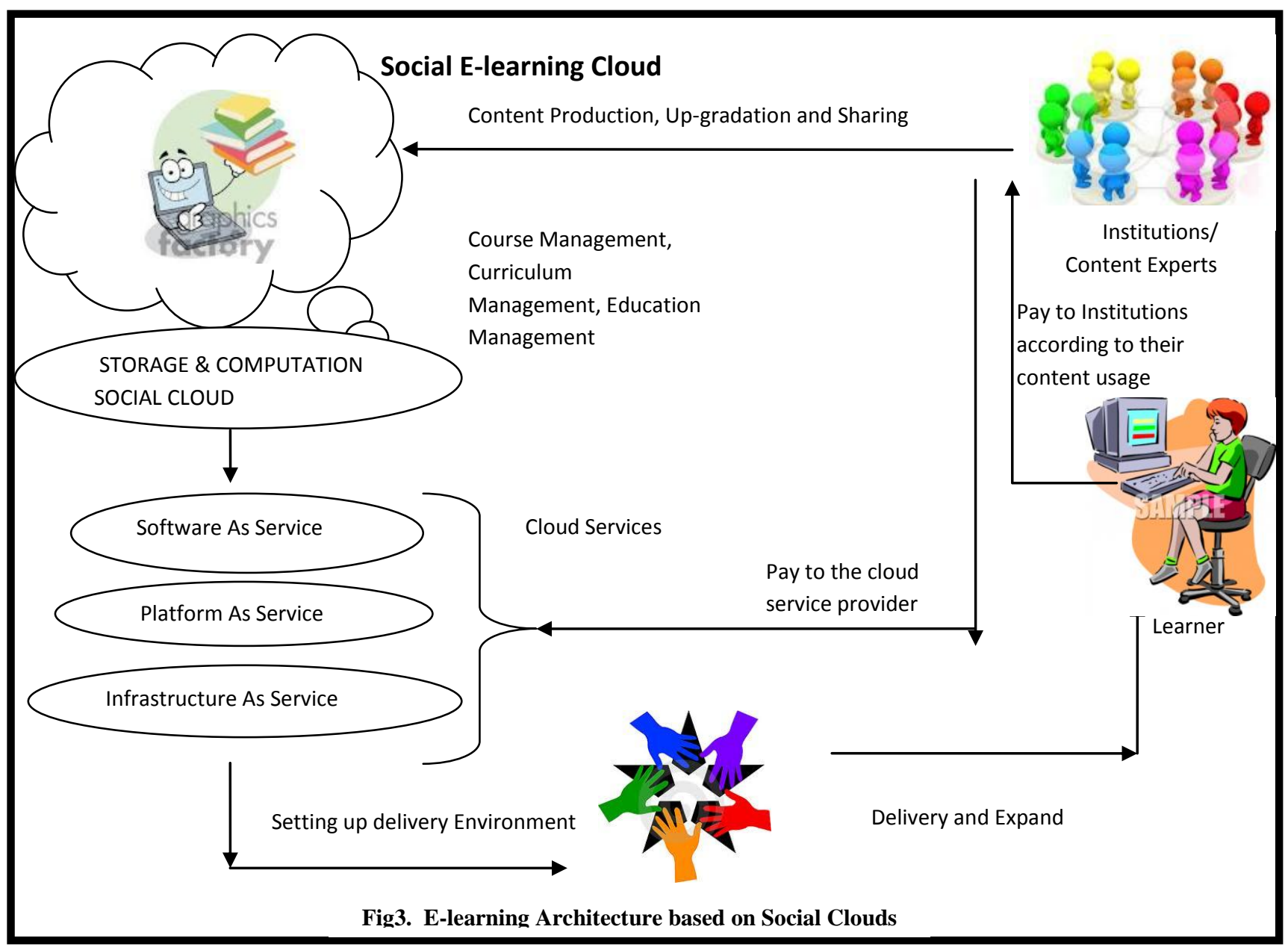

\section{INFRASTRUCTURAL SUPPORT FROM CLOUDS}

Today is the age of information technology. The facets of work and personal life are moving towards the concept of availability of everything online. In e-learning cloud computing business model, cloud provider is responsible for building and maintaining e-learning cloud, providing technical support to the e-learning cloud. Cloud users pay to the cloud provider for services and services are accessed ondemand. E-learning cloud is a migration of cloud computing technology in the field of e-learning, which is a future elearning infrastructure, including all the necessary hardware and software computing resources engaging in e-learning [8]. After these computing resources are virtualized, they can be afforded in the form of services for educational institutions, students and businesses to rent computing resources [9][10].At the lowest level, the institutions which will provide the e-learning service produce courses, content management and its up-gradation and maintenance. E-learning Cloud provides suitable resources for storage and computation. Then the service layers in cloud computing, namely, SaaS (Software as a Service), PaaS (Platform as a Service), IaaS (Infrastructure as a Service) provides services to cloud users (Institutions) for Education management, Course management etc. On the other hand it provides environment for delivery to the learner. Learner can be at any remote place. Cloud services help in efficient delivery. Learner pays to the Institution for courses undertaken and in response cloud users (Institutions) pay Cloud providers for their services.

\section{E-LEARNING ON SOCIAL CLOUD}

With the increasingly usage of Social networks and Cloud computing, users are starting to explore new ways to interact with, and exploit these developing paradigms. Social networks are the relationships that allow users to share information and forming Virtual Organizations. We propose e-learning model which utilize institutions having pre trust in each other to form a "Social Cloud", enabling institutions to share resources within the context of a Social network.

There are already existing Social networks such as MyExperiment and NanoHub for research community. They provide a virtual research environment where collaborators can share research and execute scientific workflows remotely. The same functionality can be realized using a Social Cloud deployed in an existing Social network. For example Social Storage Clouds can be used to store/share data and information (for example academic papers, scientific workflows, datasets, and analysis) within a community [7]. According to user's preference, he/she can find and combine useful learning material conveniently and economically. Each course can be assigned credentials by the respective college and required payments are done by the learner, according to the usage. At the front there is a social networking site where all the colleges are registered. Learners are assigned with a unique User id for authentication. After login, they are given a wide variety of courses offered by various providers registered. According to one's preference, a set of courses are 
offered. Learner is charged according to the courses. Each user's course information is stored in the Storage Cloud. Payment is redeemed in respective college accounts using Cloud services. Infrastructural support and other services are given by Cloud service provider as specified above. Cloud provider's payment is shared by the social network registered colleges and so providers (institutions) can be free from the building and maintenance for e-learning system and specifically focus on the application of e-learning system in order to improve teaching quality and management level.

\section{ADVANTAGES AND CHALLENGES}

The proposed model has following advantages:-

1. The service will be faster, simpler and on demand

2. The E-learning system resources will be more scalable related to overcrowded and lean periods. There will be optimized use of computing resources. Cloud will easily handle peak load situation without any additional infrastructural support.

3. As everything will be a service (SaaS, PaaS, IaaS), Learners will be having unlimited storage and resources which will give them flexibility to explore their ideas.

4. There will be high availability and reliability. As data is stored in various data centers of the cloud providers, there is less chance of data loss. Learners can use any electronic device connected with internet to access their E-learning system.

5. As Cloud computing is bringing new technologies in computing era to reduce cost and increase computing efficiency, it will be indirectly reflected in the E-learning Era.

6. Cloud computing infrastructure allows enterprises to achieve more efficient use of their IT hardware and software investments: it increases profitability by improving resource utilization. Pooling resources into large clouds cuts costs and increases utilization by delivering resources only for as long as those resources are needed[11].

7. Cloud computing infrastructure can be located in areas with lower costs of space and electricity.

The propose model still has many following challenges to become a practical working model [11]:-

1. To obtain an accurate cost and charging model :From a cloud provider's perspective, the elastic resource pool (through either virtualization or multitenancy) has made the cost analysis a lot more complicated than regular data centers, which often calculates their cost based on consumptions of static computing.

2. Security: - Security is a major issue for the cloud computing as well as social networking. Using a third party to keep and manage your data, requires faith in the cloud provider and also while sharing data in a social networking site; the authentication of the original work should be maintained by the cloud.

3. Service Level Agreement: - Cloud consumers need to ensure the quality, availability, reliability, and performance of the service provides. In other words, it is necessary for consumers to obtain guarantees from providers on service delivery. Typically, these are provided through Service Level Agreements (SLAs) negotiated between the providers and consumers.

\section{CONCLUSION AND FUTURE WORK}

This paper has presented the architecture and implementation of a Social Cloud with E-learning; a combination of Cloud computing, Social networking and E-learning. Exploring the benefits of all technologies, it provides a business model where construction and maintenance is done by cloud providers and all the E-learning providers merge to form a social group to share and enrich the teaching content as well as teaching quality. Though there are lots of challenges like charging market mechanism, Bandwidth for the content distribution, Security etc which are in front of success of the model.

\section{REFERENCES}

[1] Liang Bing, "E-learning and modern education reform", Education Information, 2001.10, pp.21, 25

[2] Zhu Chengyun, "Cloud Security: The security risks of cloud computing, models and strategies", Programmer, May.2010, pp.71- 73

[3] Xiaofei Liu, Abdulmotaleb El Saddik and Nicolas D. Georganas,, AN IMPLEMENTABLE ARCHITECTURE OF AN E-LEARNING SYSTEM,CCECE 2003, Montreal, May 2003

[4] Wang Xiaomei, Jia Xiaoqiang, "Cloud computing on the Impact of Higher Education”, Science \& Technology Information, 2010.10, pp.397-398

[5] ZHao Zhong- ping, LIU Hui-cheng , "The Development and Exploring of E- Learning System on Campus Network", Journal of Shanxi Teacher's University (Natural Science Edition), Vol.18, No.1, Mar. 2004, pp. $36-40$

[6] Xu Chuanling, Lu Hongjie, "E-learning", Software World, 2001.08, pp. 139-141

[7] Kyle Chard, Simon Caton, Omer Rana, Kris Bubendorfer, "Social Cloud: Cloud Computing in Social Networks" 2010 IEEE 3rd International Conference on Cloud Computing.

[8] Xiao Laisheng,Wang Zhengxia, "Cloud Computing: a New Business Paradigm for E-learning”, 2011 Third International Conference on Measuring Technology and Mechatronics Automation

[9] Liu Huanying, "Value and understanding for cloud computing based on middleware" ,Programmer, 2010.05. pp. 68,69

[10] Fu feng, "Cloud-based IT infrastructure of nextgeneration telecom", Mobile Communications, 2010, No. 8, pp.76-79

[11] Tharam Dillon, Chen Wu and Elizabeth Chang," Cloud Computing: Issues and Challenges" 2010 24th IEEE International Conference on Advanced Information Networking and Applications. 